\title{
Educação, Psicanálise e Sociedade : possibilidades de uma relação crítica
}

Sueli Soares dos Santos Batista

Universidade de São Paulo*

\begin{abstract}
Resumo
O objetivo deste artigo é buscar, na relação entre psicanálise e educação, possíveis elementos que ultrapassem a psicologização dos problemas educacionais essencialmente de origem social, política e econômica. Entretanto, não se descarta o aspecto frutífero desta relação, que pode ser a utilização da hermenêutica psicanalítica aliada à crítica dialética da cultura. Ao nos apropriamos de uma leitura frankfurtiana do pensamento de Freud, procuramos mostrar a importância da psicanálise para a reflexão sobre a produção do conhecimento, sobre a relação professor-aluno e para a denúncia de posturas pedagógicas meramente adaptativas e não emancipatórias. Se a ambigüidade da formação cultural, e, em sentido estrito, da educação, não pode ser eliminada simplesmente com um esclarecimento terminológico, é tarefa da Teoria Crítica contrapor os conceitos à realidade.

Portanto, formação cultural é a negação do que vivenciamos até então: semiformação socializada (Halbbildung) possível de ser apreendida na educação por meio de parâmetros pedagógicos que não têm aprofundado sua reflexão sobre a cultura e a teoria do conhecimento, sobre a democratização do ensino, a indústria cultural e os processos inconscientes existentes na relação escola-sociedade. Reivindicamos o esforço teórico em contraposição ao praticismo reinante nas intervenções feitas em prol da educação.
\end{abstract}

\section{Palavras-chave}

Educação - Psicanálise - Teoria Crítica.

\footnotetext{
Correspondência para:

Rua José Telles, 2081 -

Condomínio Itaembu-Moenda

13250-000 - Itatiba - SP

* Doutoranda do Instituto de Psicologia.
} 


\section{Education, Psychoanalysis And Society : possibilities of a critical connection}

Sueli Soares dos Santos Batista

Universidade de São Paulo*

Correspondence:

Rua José Telles, 2081 -

Condomínio Itaembu-Moenda

13250-000 - Itatiba - SP

* Ph. D. Student, Institute of Psychology.

\section{Abstract}

The aim of this paper is to search in the relationship between psychoanalysis and education for possible elements that allow us to overcome the psychologization of educational problems, which are essentially of a social, political and economical nature. However, the fruitful aspect of that relationship is not desregarded, which one is represented by the use of the psychoanalytical hermeneutics associated with the dialectical critique of culture.

By adopting a Frankfurtian reading of the Freudian thinking, the paper points out the importance of psychoanalysis to the reflection on the production of knowledge and about the relationship between student and teacher, as well as to denounce the pedagogical attitudes that are merely adaptive and does not contribute to the students' emancipation. If the ambiguity of the cultural formation and, in a strict sense, of the education, can not be eliminated by a simple terminological clarification, it is a task of the Critical Theory to weigh concepts against reality.

Cultural formation is therefore the negation of what we have experienced until now: a socialized half-formation (Halbbildung) capable of being apprehended in education through pedagogical parameters that have not deepened their reflection about culture and the theory of knowledge, about the democratization of education, about the cultural industry, and about the unconscious processes existing in the school-society relationship. One advocates the theoretical effort against the practicism dominant in initiatives taken in relation to education.

\section{Key words}

Education - Psychoanalysis - Critical Theory. 
Em face da concórdia totalitária que apregoa imediatamente como sentido a eliminação da diferença, é possivel que temporariamente, até mesmo algo da força social de libertação tenha se retirado para a esfera individual.

(Adorno, Minima Moralia)

No Brasil, a psicanálise foi acolhida nos discursos pedagógicos como forma de solucionar o problema de "crianças desajustadas", "anormalizadas pelo meio social". Assim se referiu Ramos (1939) em relação às crianças rotuladas até então de "anormais", defendendo, no campo da higiene mental, a inserção da teoria psicanalítica. Abstendo-se da análise das instituições, tarefa atribuída à sociologia, a higiene mental visava diagnosticar, prevenir e corrigir problemas de personalidade e de conduta, cuja causa estaria na influência poderosa de meios desajustados, conflitos domésticos, subnutrição, exploração do trabalho, drogas. Para Arthur Ramos, não haveria somente a "criança problema”, mas, substancialmente, "problemas da criança” socialmente determinados que não exigiriam uma crítica da sociedade como um todo, antes uma "correção" do ambiente familiar por meio da análise dos adultos. Embora Arthur Ramos detectasse a causa do desajustamento, essencialmente, como ação do meio, Porto Carrero, outro incentivador do uso da psicanálise na educação, numa perspectiva eugênica, defendia como tarefa fundamental "transformar os impulsos que vão contra o meio em impulsos úteis ao meio"(apud Mokrejs, 1989, p.9).

Apesar do avanço que representou o pensamento de Arthur Ramos nas idéias pedagógicas brasileiras, ao criticar as teorias racistas e geneticistas que predominavam na explicação do fracasso escolar, foi mantida a tradição de "não se falar da forca na casa do enforcado", ou seja, jamais atribuir o "desajustamento" à divisão de sociedade de classes (Patto, 1996). Entretanto, é possível pensar uma contribuição da psicanálise à educação em moldes não conservadores? 0 saber psicanalítico pode algo fa- zer ao indivíduo que, tendo explicitado seu inconsciente, há de retornar para uma sociedade regulada pela coisificação do consciente? Obviamente que a psicanálise se presta à crítica do conhecimento e da sociedade, mas não deixa de ser ela mesma produto social. Indíviduo e sociedade podem dispor da psicanálise como instrumento de esclarecimento, mas o desejo de não saber não pode ser relegado a segundo plano (Millot, 1979).

Não estão nos horizontes deste trabalho recuperar uma provável educação psicológica, cujas tentativas, desconectadas de uma crítica da sociedade, têm sido tão pouco proveitosas no sentido de melhorar a saúde mental dos indivíduos, muito menos sugerir uma transposição, sem mais, da clínica “..para alguma salinha encrustada no canto mais recôndito de uma escola” (Kupfer, 1982, p.70), que seria, no mínimo, obscurantismo. 0 nosso ponto de partida é a análise sobre formação cultural e psicanálise feita por T. W. Adorno.

A escola, por sua ambivalência, mereceu de Adorno um certo olhar e escuta psicanalítica a fim de clarear nela a tensão entre cultura e barbárie. Ao espaço circunscrito da escola, Adorno sugere a formação e consciência psicanalíticas para professores, pais e alunos. Porém, este esclarecimento não objetiva fins propriamente pedagógicos, mas antipedagógicos.

Pressupondo o procedimento comum à Teoria Crítica, a negação determinada que entende o conhecimento como denúncia da ilusão, Adorno deposita na escola as poucas possibilidades de fazer frente à barbárie civilizada. Se ao esforço da escola for aliada a psicanálise - por exemplo, os tabus inerentes aos professores sendo pensados e dirimidos na própria formação profissional em vez de serem a sua base (Adorno, 1996) -, não quer dizer que tenhamos achado a solução única e definitiva entretanto, “...um esclarecimento um pouco suficiente e apenas parcialmente eficiente ainda é melhor do que nenhum" (Adorno, 1996, p.114). 
Essa ilustração via escuta psicanalítica e auto-reflexão crítica - numa palavra, o pensamento - e a experiência, a partir da qual a desbarbarização seja possível, têm a seu favor a ação antipedagógica da psicanálise que não deve ir ao encontro do aperfeiçoamento, mas da desarticulação da escola tal qual a conhecemos, vivenciamos e perpetuamos. As doutrinas pedagógicas são essencialmente egóicas, ao buscarem o controle e a previsibilidade do desenvolvimento cognitivo e emocional da criança, sem levar em conta a impossibilidade estrutural desse domínio. Uma educação analítica, segundo Kupfer (1992, p.75), só seria possível no momento em que a educação renunciasse ao seu próprio fundamento. Há que se fazer, portanto, uma diferenciação entre educação e discurso sobre educação, a pedagogia. O conhecimento da impossibilidade de controlar o inconsciente não leva simplesmente a uma posição ética extremamente valiosa. Leva-nos a poder pensar uma educação não totalitária e emancipatória.

Adorno e Horkheimer (1994) analisaram o sentido egóico das doutrinas pedagógicas em seu caráter persecutório da capacidade mimética para garantir a produtividade e a dominação:

0 rigor com que os dominadores impediram no curso dos séculos a seus próprios descendentes, bem como as massas dominadas, a recaída em modos de vida miméticos - começando pela proibição de imagens na religião, passando pela proscrição social dos atores e dos ciganos e chegando, enfim, a uma pedagogia que desacostuma as crianças de serem infantis - é a própria condição da civilização. A educação social e individual reforça nos homens seu comportamento objetivamente enquanto trabalhadores e impede-os de se perderem nas flutuações da natureza ambiente. Toda diversão, todo abandono tem algo de mimetismo. Foi se enrijecendo contra isso que o ego se forjou. É através de sua constituição que se realiza a passagem da mímese refletora para a reflexão controlada. (p.169)

0 que é fundamental não é a reapropriação do mimético como magia e regressão: a mímesis indicaria muito mais uma dimensão essencial do pensar, essa dimensão de aproximação não violenta, lúdica. Uma aproximação do outro que consiga compreendê-lo sem prendê-lo e oprimi-lo, conhecimento sem violência nem dominação (Gagnebin, 1997, p.103). Esse conhecimento só seria possível com o reconhecimento do estranho, como definiu Freud: o secretamente familiar que foi submetido à repressão, mas retornou, enfim, o que deveria ter permanecido oculto mas veio à luz. (Freud, 1919, vol. XVII).

Esse estranho, para Adorno e Horkheimer, seria tudo o que diz respeito à natureza não totalmente conformada pelo processo civilizatório, que nos remete à mímese originária, desapossando o sujeito de si mesmo, como a corporeidade, a experiência estética, o sofrimento. 0 acolhimento e convivência com os conflitos e alegrias da alteridade não estão nos limites de uma terapia, já que esse outro está socialmente localizado nos "desajustados”, “anormais”, "fracos” que não se coadunam com os impositivos de produtividade, eficiência e obediência. Se "tudo o que não se ajustou inteiramente ou que fira os interditos em que se sedimentou o progresso secular tem um efeito irritante e provoca uma repugnância compulsiva" (Adorno e Horkheimer, 1994, p.168), a ética da compaixão exige não só o autoconhecimento via esclarecimento psicanalítico, mas uma transformação social:

No modo de produção burguês, a indelével herança mimética de toda práxis é abandonada ao esquecimento. Os homens obcecados pela civilização só se apercebem de seus próprios traços miméticos, que se tornaram tabus, em certos gestos e comportamentos que encontram nos outros e que se destacam em seu 
mundo racionalizado como resíduos isolados e traços rudimentares verdadeiramente vergonhosos. (p.169-70)

Portanto, a crítica às relações de produção e o conhecimento daí decorrente permitem superar as teorias explicativas do fracasso, do desajustamento, que procuram nivelar e esvaziar as contradições do processo civilizatório, localizando-as no biológico e/ou silenciando as determinações sociais.

Se a construção civilizatória está fundada na negação do inconsciente, da capacidade mímética, para que se possa afirmar os poderes da consciência, da razão, da exploração do trabalho, a maior contribuição que a psicanálise pode dar à educação é, justamente, a de mostrar a sua impossibilidade. Kupfer (1992, p.76) afirma que "é preciso deixar os exageros à parte para buscar um ponto de equilíbrio em que o educador possa se beneficiar do saber psicanalítico". Para Adorno, "na psicanálise nada é verdadeiro a não ser seus exageros" (1993, p.41). Neste ponto, talvez seja preciso procurar não o ponto de equilíbrio, mas o de desequilíbrio, em que o espaço do conflito possa ser explicitado e aquilo que foi silenciado possa ser ouvido. Uma pedagogia que levasse a sério o fenômeno da consciência contraditória não seria intervencionista, dirigista, totalitária, como considerou Marilena Chauí (1979), antes trabalharia pela resistência. Mas isso equivale à pedagogia pensar a sua historicidade, debruçar-se sobre si mesma, para tornar possível a educação emancipatória.

0 que entendemos como ação antipedagógica da psicanálise foi bem exemplificado por Marilena Chauí:

Suponhamos um professor que tendo trabalhado as idéias de Freud e de Marx se decidisse pela crítica do humanismo burguês. A partir desse momento, a educação seria para ele um problema e não uma solução, pois que há de se formar um outro quando se conhece a força irredutível do inconsciente e a dissimulação sistemática da exploração através da moral da responsabilidade? Para tal professor, formar não seria informar aos alunos acerca dessas questões e discuti-las com eles? Mas como poderia esse professor ter a pretensão de formar para a "liberdade" conhecendo o papel corrosivo e repressivo da cultura como superego e o significado de uma sociedade que se reproduz pela reposição da repressão (do corpo e do espírito) através da exploração econômica? Não estaria, esse professor, tocando justamente nos limites e nas ilusões do humanismo? (1979, p.35)

Esta hipótese só pode ser levantada, vejamos bem, numa perspectiva em que se vislumbre não apenas a psicanálise, mas o pensamento de Marx. Este dado é fundamental nessa situação hipotética citada por Chauí. É uma certa leitura marxista de Freud que pode tornar fecunda a relação entre psicanálise e educação. Nas seguintes considerações de Adorno, observamos um posicionamento crítico ante os "limites e ilusões do humanismo", a partir de uma leitura de Freud e Marx:

...o conhecimento psicológico defendido como teoria justamente por Freud (...) encontra-se em concordância também com a possibilidade de sublimar de tal modo os chamados instintos de agressão, acerca dos quais inclusive ele manifestou concepções bastante diferentes durante sua vida, de maneira que justamente eles conduzam a tendências produtivas. Portanto, creio que na luta contra a barbárie ou em sua eliminação existe um momento de revolta que poderia ele próprio ser designado como bárbaro, se partíssemos de um conceito formal de humanidade. Mas já que todos nós nos encontramos no contexto de culpabilidade do próprio sistema, ninguém estará inteiramente livre de traços de barbárie, 
e tudo dependerá de orientar esses traços contra o princípio da barbárie, em vez de permitir seu curso em direção à desgraça. (p.158)

A palavra de ordem é, portanto, a defesa da condição imediata da sobrevivência da humanidade, historicamente ameaçada, não de um conceito anistórico de humanidade. Para Adorno não basta a psicanálise para tal, pois a estrutura dinâmica do psiquismo apresentada por Freud - as relações entre o ld, Ego e Superego - já não são suficientes no capitalismo monopolista:

A psicanálise apresentou a pequena empresa interior que assim se constituiu como uma dinâmica complicada do inconsciente e do consciente, do id, ego e superego. No conflito com o superego, a instância de controle social no indivíduo, o ego mantém as pulsões dentro dos limites da autoconservação... Mas, na era das grandes corporações e das guerras mundiais, a mediação do processo social pelas inúmeras mônadas mostra-se retrógrada. Os sujeitos da economia pulsional são expropriados psicologicamente e essa economia é gerida mais racionalmente pela própria sociedade. A decisão que o indivíduo deve tomar em cada situação não precisa mais resultar de uma dolorosa dialética interna da consciência moral, da autoconservação e das pulsões. Para as pessoas na esfera profissional, as decisões são tomadas pela hierarquia que vai das associações até a administração nacional; na esfera privada, pelo esquema da cultura de massa, que desapropria seus consumidores forçados de seus últimos impulsos internos. As associações e as celebridades assumem as funções do ego e do superego, e as massas, despojadas até mesmo da aparência da personalidade, deixam-se modelar muito mais docilmente, segundo os modelos e palavras de ordem dadas, do que os instintos pela censura interna. Se, no liberalismo, a individuação de uma parte da população era uma condição da adaptação da sociedade em seu todo ao estágio da técnica, hoje, o funcionamento da aparelhagem econômica exige uma direção das massas que não seja perturbada pela individuação... A irracionalidade da adaptação dócil e aplicada à realidade torna-se, para o indivíduo, mais racional do que a razão. (Adorno e Horkheimer, 1994, p.189-90)

Assim, a "obra de cultura", objeto da psicanálise, expressa na sentença "onde havia o ld, que passe a haver o Ego" (Freud, vol. XXIl, p.84), não se consubstancia devido ao sitiamento da subjetividade e ao encapsulamento quase automático do inconsciente. Tanto que já não é possível falar sem ressalvas de "sublimação dos instintos" pela qual a civilização teria se engendrado até então mas de sua domesticação para aumentar a produtividade e o consumo. A criatividade e a fruição pela arte estão reduzidas à liberação e ao imediato adestramento do inconsciente via tecnicismo e indústria cultural. 0 resultado disto não pode ser cultura porque tem por princípio e finalidade a indiferenciação. Os indivíduos de seres sociais conformam-se, então, à categoria de seres socializados que é a sua própria negação. Vivemos em uma situação em que para muitos - no entender de Adorno (1993) - já é um descaramento dizerem "Eu". Daí a necessidade de uma crítica que pense a "coisificação das almas": "A técnica é dona não só de seus corpos, mas também de seus espíritos..." (Adorno e Horkheimer, 1969, p.102). A tarefa da psicanálise, nesse sentido, seria a de denunciar a socialização progressiva, resultado da fragilização do ego nas atuais condições de sobrevivência material perpetuadoras da bárbarie:

Como hoje em dia é extremamente limitada a possiblidade de mudar os pressupostos objetivos, isto é, sociais e políticos que geram tais acontecimentos, as tentativas de se contrapor à repetição de Auschwitz são impelidas necessariamente para o lado subjetivo. (Adorno, 1995, p.121) 
Não pode haver crítica da cultura sem crítica das relações de trabalho e de produção, pois a cultura se constitui na materialidade e na historicidade. Mas refletir sobre ela pressupõe um olhar que ultrapasse o desvelamento da luta de classes que ela estaria ocultando. Sem esse horizonte fazemos apenas o que Adorno chama de "crítica cultural" convocada e estreitamente atrelada a um conceito acrítico da cultura, em que o crítico cultural pensa ter concluído sua tarefa, ao fazer a correspondência entre o objeto a ser criticado e os interesses de classes que ele reflete, a crítica imanente prossegue buscando o conteúdo de verdade implícito na falsidade. A psicanálise, neste sentido, é um momento privilegiado da crítica imanente, pois Freud analisou com seriedade o conteúdo de verdade das formações psíquicas.

Adorno explicita bem o que entende por crítica imanente/dialética da cultura, em linhas gerais, ao considerar que esta postura ante o objeto é a de não hipostasiar os padrões culturais nem a de se restringir a termos operacionais, a fim de fazer justiça a ela, o que não significa um envolvimento completo no objeto e, sim, transcender da consciência, como categorias do entendimento, para além da imanência. "Só será capaz de acompanhar a dinâmica própria do objeto quem nele não estiver completamente envolvido" (Adorno, 1994, p.86). Esse duplo movimento em direção ao objeto (envolvimento e não envolvimento) é subsidiário da crítica que Freud faz à cultura, ao considerar que ela se faz para e contra os interesses do indivíduo. Importante, também, para considerar a impossibilidade de estarmos completamente e totalmente alheios a mecanismos ideológicos.

0 educador precisa ser um crítico da cultura, mais do que um cidadão sinceramente preocupado com a cidadania. Crítica imanente e dialética da cultura e auto-reflexão crítica são pressupostos fecundos de uma relação entre psicanálise e educação que tem como ponto de partida e de chegada a transformação das condições objetivas. A psicanálise, portanto, não é incompatível com a educação, mas com as doutrinas pedagógicas, ao possibilitar, no mínimo, um redirecionamento na formação do professor.

Se as descobertas freudianas, como o inconsciente e a hermenêutica psicanalítica, não coadunam com as promessas da cultura, elas podem ser referenciais de crítica do conhecimento e da educação, pela qual este conhecimento tem se legitimado. A escola, surgindo como resposta ao nascimento do Estado, da família, da propriedade privada e da divisão social do trabalho, o mal estar na educação é decorrente do mal-estar na civilização. 0 subtrair-se à confrontação com o horror é permitir que ele se perpetue. 0 desconhecimento diante do sofrimento provocado pelos mecanismos da dominação é ela própria (Adorno, 1993). Em outras palavras:

...a educação precisa levar a sério o que já de há muito é do conhecimento da filosofia: que o medo não deve ser reprimido. Quando o medo não é reprimido, quando nos permitirmos ter realmente tanto medo quanto esta realidade exige, então justamente por essa via desaparecerá provavelmente grande parte dos efeitos deletérios do medo inconsciente e reprimido. (Adorno, 1995, p.88)

Não é de se admirar que o processo educativo tenha fracassado. Ao silenciar, ocultar, ou simplesmente desconhecer os seus tabus e seu lado obscuro, a comunidade escolar - e, em última instância, a civilização - vê-se aprisionada por este oculto que se manifesta, por exemplo, no que Adorno (1996, p.111) chama de "dupla hierarquia", observável na escola, em que a investigação pedagógica deveria prestar especial atenção: “...a hierarquia oficial, conforme o intelecto, o desempenho, as notas, e a hierarquia não-oficial, em que a força física, o 'ser 
homem' e todo um conjunto de aptidões prático-físicas não honradas pela hierarquia oficial desempenham um papel”.

"Ser homem" coloca-se em oposição ao esforço intelectual. Nesta dupla hierarquia, na qual se expressa a divisão entre trabalho físico e trabalho intelectual, há também o problemático da competição - escore de notas, classes selecionadas (as conhecidas turmas “A”) -, cujo fortalecimento é contrário a uma educação humana. Nesse caso, há uma aparente valorização do trabalho intelectual porque, afinal, se o importante é ser o mais forte - não importa se física ou mentalmente -, a formação cultural já está abolida porque indiferenciada com o seu contrário. Adorno e Horkheimer (1994, p.195), ao analisarem os que têm resposta para tudo, consideram que: "os inteligentes sempre facilitaram as coisas para os bárbaros, porque são estúpidos”. Se a escola pretende humanizar o indivíduo, há que se deter sobre o inumano no próprio humano.

É preciso assumir a ferida narcísica provocada pela descoberta do inconsciente, reconhecendo que a barbárie implícita na cultura não deve estar a serviço de uma fragilização do professor. 0 saber não se impõe, mas não pode dispensar a autoridade. 0 ser humano autônomo e, portanto, emancipado não constitui simplesmente o protesto contra qualquer tipo de autoridade. Adorno entende o momento da autoridade como pressuposto da emancipação. Mas a glorificação e a conservação deste momento constitutivo da individualidade leva ao sentido contrário do desejável, ou seja, à menoridade no sentido kantiano: a incapacidade de se servir de seu próprio entendimento. As pessoas tornam-se emancipadas a partir da identificação com a autoridade, com a posterior frustração com ela e a sua superação. Porém, ocorre bastante amiúde a identificação com o agressor.

0 processo de adaptação, que se dá de forma dolorosa, passa, necessariamente, por um exagerado realismo em relação a si mesmo
(Adorno, 1995). Adorno entende que a crítica a este realismo supervalorizado, estofo da identificação com o agressor, precisa ser avaliado, sobretudo, na primeira infância.

Analisar a ambivalência da relação professor-aluno e sociedade-professor é procurar entender a aversão ante a docência que não se limita apenas às considerações a respeito de ser uma profissão mal remunerada. Há nesta aversão processos inconscientes que já não possuem base nos fatos objetivos, mas dão conta de motivações subjetivas pouco discutidas e por isso mesmo preocupantes. Ser professor implica carregar a imagem de escriba, de monge destituído de poderes temporais, de alguém detentor de um conhecimento pouco eficiente num mundo em que, implicitamente, a força física determina considerável parte da vida social.

Isto implica que, apesar da supressão dos castigos físicos na escola e os tão propalados direitos da criança, há a imagem inconsciente do professor como torturador, carcereiro, verdugo, daquele que tem poder sobre seres fragilizados por sua faixa etária ou por sua ignorância. Perante a escassez estrutural de nossas escolas, o professor não consegue ir muito além de um guardador de crianças.

De qualquer maneira, a desigualdade inerente à relação pedagógica põe o professor em situação suspeita e de eterno vigilante, tornando-o, ao mesmo tempo, um eterno vigiado em suas reações, em suas preferências afetivas - que, aliás, não deve expressar, sob pena de ser considerado injusto. De castrador o professor converte-se em castrado:

Por um lado, ele não tem função erótica; por outro, desempenha um grande papel erótico, para adolescentes deslumbrados, por exemplo. Mas na maioria dos casos apenas como objeto inatingivel; basta que se observem nele traços de simpatia, para difamá-lo como injusto. (Adorno, 1995, p.107-108) 
Essa exclusão quase sempre apenas formal da esfera erótica, escamoteada as mais das vezes em sublimação - o professor tem que ser exemplo de discrição e autocontrole como arauto da civilização -, é refletida na consciência mutilada que não tolera a livre expressão do corpo. A disposição das carteiras, a ordem "fique quieto" são mais do que posturas disciplinares: é a imobilização física expressando a clausura do espírito. A indiferença com a própria dor e a dor do outro é a marca desta educação para a disciplina mediante o rigor, imagem encobridora do sadismo e do masoquismo, tão caros ao fascismo.

As relações objetais na escola mereceram uma atenção especial de Adorno. Justamente por não serem discutidas, transformam-se em tabus, proibindo a distinção entre trabalho objetivo e afeto pessoal. Um professor plenamente objetivo, ou seja, profissional estritamente, apareceria inumano e frio, mas dar vazão à sua efetividade sem que possa ter controle sobre isto é subsumir-se às representações que se faz dele. Para Adorno (1995), os professores não deveriam reprimir seus afetos para depois deixá-los brotar racionalizados, sem reconhecê-los perante si e os demais:

\footnotetext{
Provavelmente um professor que diz: "sim, eu sou injusto, eu sou uma pessoa como vocês, a quem algo agrada e algo desagrada" será mais convincente do que um outro apoiado ideologicamente na justiça, mas que acaba inevitavelmente cometendo injustiças reprimidas. (p.113)
}

Isto nos remete à questão da avaliação escolar e às implicações que o comportamento disciplinar do aluno têm sobre ela. Como o professor pode efetivamente avaliar o aluno, de forma mais humana e justa, se não é possível para ele se dar conta das contradições inerentes a ele próprio? Parece-nos que não se trata apenas de ética profissional, mas de se colocar na mesa das discussões pedagógicas o quanto de subjetivo tem a relação professor-aluno e não simplesmente colocar o professor na posição de neutralidade para avaliar alguma coisa. No caso de reprovação, fica-se à mercê - e isto é a expressão da democratização do ensino - de veementes apelações verbais e formais (recursos em instâncias superiores à escola), bastando para que sejam válidas apenas algum erro ou esquecimento do professor ou do coletivo de professores no processo de avaliação. Embora os discursos não sejam tão explícitos, o professor, efetivamente, não é considerado apto para avaliar o seu trabalho e a repercussão dele nos alunos. Incerteza, debilidade, falsidade e injustiça são conceitos que envolvem a docência, sem que isso possa ser dito claramente e reconhecido.

A exigência de objetividade para o professor que deve conter, reprimir tudo o que for subjetivo na sua relação com os alunos também está relacionada à manutenção de uma sociedade que teme o diferente e o potencial transformador contido no particular. Uma compreensão crítica do que se pretende com esta objetividade e o que há de tão temível na subjetividade da relação professor-aluno talvez pudesse trazer aos nossos horizontes alguma perspectiva de humanização. 0 sujeito pode guardar em si um poder objetivo ainda maior que categorizações abrangentes e pré-estabelecidas - os chamados critérios de cientificidade no positivismo ou o conceito de estilo nas artes, por exemplo. No mundo totalmente administrado, o processo persecutório contra a objetividade do sujeito (entendida como subjetividade num sentido de imoralidade e incompetência para discernir) é utilizado para deixá-lo na eterna impotência. Assim, a objetividade, que tem por fim desmascarar posturas ideológicas, é, ela mesma, instrumento ideológico para tratar a todos como coisas (Adorno, 1993). Abordar a subjetividade criticamente permite analisar e transformar as condições 
objetivas não só do indivíduo, mas da sociedade que o sitia. As explicações psicológicas são parciais, mas necessárias, à medida que podem desmascarar as forças irracionais, que, em nome da razão, dominam coercitivamente $o$ indivíduo.

\section{Referências bibliográficas}

ADORNO, T. W. Consignas. Buenos Aires: Amorrortu, 1972. . Educação e emancipação. São Paulo: Paz e Terra, 1995 . Intervenciones: nueve modelos de critica. Venezuela: Monte Avila, 1969. . Minima Moralia. São Paulo: Ática, 1993. .; HORKHEIMER, M. Dialética do esclarecimento: fragmentos filosóficos. Rio de Janeiro: Jorge Zahar, 1994.

CHAUÍ, Marilena. Ideologia e Educação. Revista Educação e Sociedade, São Paulo, n.5, p.24-40.

COHN, Gabriel (org.) Theodor Adorno. 2a. ed. São Paulo: Ática, 1994. (Coleção grandes cientistas sociais) FREUD, Sigmund. Obras completas. v.17, v.22. Rio de Janeiro: Imago Editora, 1976.

KUPFER, Maria Cristina. Freud e a educação: o mestre do impossível. 2. ed. São Paulo: Ed. Scipione, 1996.

KUPFER, Maria Cristina. Relação professor- aluno: uma leitura psicanalítica. São Paulo; 1982. Dissertação (Mestrado) Instituto de Psicologia da USP.

GAGNEBIN, Jeanne-Marie. Sete aulas sobre linguagem, memória e história. Rio de Janeiro: Ed. Imago, 1997.

MILLOT, C. Freud anti-pédagogue. Paris: Editions du Seuil, 1979.

MOKREJS, Elisabete. Psicanálise e educação: Júlio Pires Porto Carrero e a pedagogia eugênica na década de trinta no Brasil. Revista da Faculdade de Educação, São Paulo, v.15, n.1, p.5-15, jan./jun. 1989.

MOKREJS, Elisabete. Psicanálise e educação - Arthur Ramos - um episódio da História da Educação no Brasil. Revista da Faculdade de Educação, São Paulo, v.13, n.1, p.91-104, 1987.

PATTO, Maria Helena Souza. A produção do fracasso escolar. São Paulo: T.A. Queiroz Ed., 1996.

RAMOS, Arthur. A criança problema: a higiene mental na escola primária. São Paulo: Nacional, 1939. 